\title{
OS PROJETOS FINANCIADOS PELO BANCO MUNDIAL PARA O ENSINO FUNDAMENTAL NO BRASIL*
}

\author{
Ireni Marilene Zago Figueiredo ${ }^{* *}$
}

\begin{abstract}
RESUMO: No contexto da crise da dívida externa, a educação é concebida como parte do conjunto das reformas econômicas. Desse modo, os projetos financiados para o ensino fundamental, pelo Banco Mundial, fazem parte do conjunto dos empréstimos de ajustes estruturais e setoriais. Esses empréstimos possuem características comuns entre elas a de dar suporte às reformas institucionais e econômicas e racionalizar os programas de investimento do setor público. $\mathrm{Na}$ década de 1990 , os projetos financiados para o ensino fundamental apoiaram e orientaram as políticas para enfrentar o fracasso escolar (evasão e repetência), as quais contemplaram o processo de avaliação e de concorrência e os critérios de qualidade, de racionalidade econômica e de produtividade.
\end{abstract}

Palavras-chave: Educação fundamental. Brasil e estados. Financiamento externo. Banco Mundial.

\section{WORLD BANK FINANCED PROJECTS FOR BRAZILIAN BASIC EDUCATION}

ABSTRACT: On the context of the external debt crisis, education has been conceived of as an integrant part of the set of economic reforms. The World Bank financed projects for Basic Education are thus included in the loans for structural and sectorial adjustments. Such loans share characteristics and are aimed to support the institutional and economic reforms and rationalize public sector

\footnotetext{
* Este texto é resultado de parte das reflexões sistematizadas em tese de doutorado defendida na Faculdade de Educação da Universidade Estadual de Campinas (UniCAmP), área de concentração História, Filosofia e Educação, sob orientação da profa dra $^{a}$ Maria Elizabete Sampaio Prado Xavier.

** Doutora em Educação, docente do Colegiado do Curso de Pedagogia e do Programa de Pós-Graduação em Educação da Universidade Estadual do Oeste do Paraná (UnIOESTE). E-mail: irenifigueiredo@unioeste.br
} 
investment programs. In the 1990s, the financed projects for Basic Education, which supported and guided the politics to face school failure (dropout and repetition), considered the evaluation and competition process and the criteria of quality, economic rationality and productivity.

Key words: Basic Education. Brazil and States. External financing. World Bank.

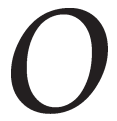

s desdobramentos e as contradições produzidos nas décadas de 1970 e 1980 constituem particularidades e peculiaridades para a compreensão do processo que emergiu durante a década de 1990. Desse modo, as consequências da crise financeira internacional, na década de 1970, e da "crise da dívida" dos países latino-americanos, na década de 1980, contribuíram para que os organismos multilaterais de financiamento, o Fundo Monetário Internacional (FMI), o Banco Internacional para a Reconstrução e o Desenvolvimento (BIRD)/ Banco Mundial e o Banco Interamericano de Desenvolvimento (BID), assumissem a liderança no processo de renegociação da dívida desses países, por meio de uma série de condicionalidades econômico-financeiras e político-ideológicas circunscritas aos Planos de Estabilização e aos empréstimos para os ajustes estruturais (1980) e setoriais (1983).

Nos anos 80, a eclosão da crise de endividamento abriu espaço para uma ampla transformação do papel até então desempenhado pelo Banco Mundial e pelo conjunto dos organismos multilaterais de financiamento (...). De um Banco de Desenvolvimento, indutor de investimentos, o Banco Mundial tornou-se guardião dos interesses dos grandes credores internacionais, responsável por assegurar o pagamento da dívida externa e por empreender a reestruturação e abertura dessas economias, adequando-se aos novos requisitos do capital globalizado. (Soares M., 1998, p. 20)

O enfoque do Banco Mundial na educação ampliou-se no final da década de 1960, acabando por destacá-la como uma de suas políticas setoriais durante a década de 1970 . Com a perda das atribuiçóes da UNESCO para o Banco Mundial e, posteriormente, com a saída dos EUA, em 1984, da UNESCO, o debate sobre a educação foi se transformando em assunto de negócios, de banqueiros e de estrategistas políticos (Leher, 1998). 
A implementação de ajustes estruturais e setoriais, empreendidos no Brasil, converge e articula os condicionantes requeridos às políticas macroeconômicas. Os empréstimos de ajuste estrutural objetivam promover uma maior abertura comercial, produtiva e financeira e os empréstimos setoriais sustentam as condicionalidades de ordem macroeconômica na perspectiva de promover as reformas estruturais, tendo em vista as novas condicionalidades impostas pela economia internacional aos diversos setores sociais e econômicos nacionais. Seguindo o "Progress Report”, do Banco Mundial, esses empréstimos apresentam características comuns, as quais compreendem: o suporte de reformas institucionais e econômicas; a ênfase na racionalização dos programas de investimento do setor público; e a pressuposição de uma política macroeconômica apropriada ao indispensável objetivo de estabilidade (Gonzalez et al., 1990).

Notadamente durante os governos Fernando Collor de Mello (1990-1992), Itamar Franco (1992-1994), Fernando Henrique Cardoso (1995-2002) e Luiz Inácio Lula da Silva (2003-2007) há um processo de intensificação de reformas nas áreas econômica, social e política. A realização das reformas na sociedade brasileira tem como parâmetro as condicionalidades provenientes dos empréstimos de ajustes estruturais e setoriais. A reforma educacional, portanto, é uma das componentes dos empréstimos de ajustes estruturais e setoriais, bem como do processo de reforma e modernização do Estado brasileiro.

A necessidade de promover reformas na educação está inscrita no contexto mais amplo do processo de reestruturação econômica do país. A argumentação para justificar a reforma educacional centra-se na superação da falta de qualidade, de produtividade, de requerimentos educacionais à modernização do país e à integração à globalização. As reformas são anunciadas e realizadas “(...) com a crença orientada sempre na direção do mercado e da competitividade internacional, sustentadas na estratégia de 'desenvolvimento da competitividade para integração da economia brasileira à globalização econômica'” (Deitos, 2005, p. 163; grifos do autor).

Nas formulações do Banco Mundial o argumento é de que a falta de reformas no financiamento e na administração da educação vem acarretando custos econômicos, sociais e políticos para os países em desenvolvimento. 
Os projetos financiados pelo Banco Mundial para o ensino fundamental no Brasil

A educação é a pedra angular do crescimento econômico e do desenvolvimento social e um dos principais meios para melhorar o bem-estar dos indivíduos. Ela aumenta a capacidade produtiva das sociedades e suas instituiçóes políticas, econômicas e científicas e contribui para reduzir a pobreza, acrescentando o valor e a eficiência ao trabalho dos pobres e mitigando as consequências da pobreza nas questōes vinculadas à população, saúde e nutrição (...). (Banco Mundial, 1992, p. 2 apud Torres, 1998, p. 131)

(...) é certo que as taxas mais elevadas de repetência e consequentemente evasão entre crianças de grupos de baixa renda são um dos principais fatores que contribuem às disparidades de renda no Brasil, e também é um empecilho à produtividade do trabalho e ao crescimento econômico. (Banco Mundial, 1993, p. 23)

(...) A educação é um importante instrumento de promoção do crescimento econômico e da redução da pobreza. (...) A educação pode ajudar a reduzir a desigualdade, proporcionar novas oportunidades aos pobres e, consequentemente, aumentar a mobilidade social. (Banco Mundial, 1995, p. xv-xviii)

É preciso considerar, também, que existe um consenso entre o BID e o Banco Mundial, quanto ao Estado oferecer os serviços essenciais básicos de educação e de saúde. Esses serviços têm como meta manter a pobreza em níveis suportáveis, atendendo às demandas sociais críticas para administrar os efeitos recessivos das duras políticas de ajuste econômico. Nessa direção, a intervenção do Estado nas áreas de educação e saúde básicas contribui para criar as condições favoráveis mínimas para implementar as políticas de ajuste econômico, visando contribuir com a estabilidade política e social (Figueiredo, 2006).

Na década de 1990, a intervenção do Banco Mundial na política educacional brasileira teve um total de financiamento combinado de cerca de US\$ 1 bilhão, com a aprovação de 6 projetos que contemplaram 13 estados brasileiros. Dos 6 projetos, 2 continuaram para a Região Nordeste, com abrangência para todos os estados: "Educação Básica no Nordeste II” (Maranhão, Ceará, Pernambuco e Sergipe) e "Educação Básica no Nordeste III" (Piauí, Rio Grande do Norte, Paraíba, Alagoas e Bahia). Os demais projetos foram para os estados de Minas Gerais - "Projeto de Melhoria da Qualidade da Educação Básica em Minas Gerais"; São Paulo - "Projeto Inovações na Educação Básica em São Paulo" (INOVAÇốES); Espírito Santo - "State of Espírito Santo 
Basic Education Project"; e Paraná - "Projeto Qualidade no Ensino Público do Paraná" (PQE). Os projetos financiados visavam apoiar a estratégia e as prioridades do Banco Mundial para o setor, exigindo um envolvimento substancial do Banco em supervisão (Banco Mundial, 1994, p. 16).

O processo de negociação de projetos para o setor educacional, entre o Brasil e os organismos internacionais, está permeado por contradiçôes e interferências de interesses econômicos e políticos nacionais e internacionais. Assim, convém destacar que, na análise da dinâmica política e financeira que permeia as relaçóes entre os Estados nacionais e os organismos multilaterais durante o processo de negociação, aprovação, revisão e desenvolvimento dos projetos financiados, duas simplificações devem ser evitadas. A primeira é a de acreditar num alinhamento incondicional entre as políticas elaboradas no contexto das instituições multilaterais e as políticas nacionais que aceitam e ratificam suas orientaçôes em função das necessidades dos recursos que as acompanham. A segunda é a de acreditar na ausência de contradições no contexto das negociações, tanto entre os técnicos dos organismos multilaterais quanto entre os responsáveis pelas políticas nacionais (Haddad, 1998).

Isso significa que a receptividade aos acordos internacionais não é homogênea entre os diferentes segmentos políticos e técnicos da administração pública (Fonseca, 1998, p. 87).

Com base na experiência brasileira ao longo de mais de vinte anos, é possível afirmar que a cooperação técnica e financeira do Banco Mundial não constituiu uma interação neutra, mas um mecanismo de difusão de concepçóes internacionais, especialmente aquelas que emanam do próprio órgão financiador. Estas incluem desde aspectos instrumentais, como modelos de planejamento e de gestão de projetos, até as formulações conceituais e ideológicas, capazes de orientar a agenda do setor sob financiamento. (Oliveira; Fonseca, 2001, p. 64)

A dinâmica da relação econômico-política, que perpassa as negociações e envolve os interesses nacionais e internacionais, inclui a participação dos estados no processo, para justamente definir as ações que estão condicionadas às orientações e propostas prescritas pelo Banco Mundial. Pode-se verificar que as condicionalidades referentes às orientações e propostas do Banco Mundial estavam presentes, por 
Os projetos financiados pelo Banco Mundial para o ensino fundamental no Brasil

exemplo, no processo de negociação dos projetos com os estados da Região Nordeste (Nordeste II) e o estado de Minas Gerais (Projeto Qualidade na Educação Básica).

O projeto "Educação Básica no Nordeste II" (Nordeste II) foi preparado pelo Ministério da Educação e do Desporto no nível federal e pelas Secretarias de Educação dos estados do Ceará, Maranhão, de Sergipe e de Pernambuco, com assistência do Banco Mundial (Banco Mundial, 1993).

No estado de Minas Gerais, como uma condição para apresentação ao Conselho Diretor do Banco Mundial, o estado teria de fornecer ao Banco a versão final do Projeto Qualidade na Educação Básica, baseada na versão preliminar discutida na fase das negociações (Banco Mundial, 1994).

A flexibilidade do Banco Mundial em negociar também tem a finalidade de diminuir os riscos financeiros e políticos dos projetos. Essa predisposição foi observada na alteração de cláusulas e de rubricas dos componentes ( $\mathrm{PQE} / \mathrm{PR}$ ) e na possibilidade de transferência de recursos para outros estados (Nordeste II).

As implicações financeiras da prorrogação do Projeto Qualidade no Ensino Público do Paraná (PQE), para dois anos, resultaram no aumento do custo em aproximadamente US\$224,4 milhōes, ocasionando um aumento de $13 \%$ sobre a estimativa inicial. Já os recursos da contrapartida aumentaram 25\% acima da estimativa inicial. No PQE/PR ocorreu a alteração de rubricas, na medida em que recursos dos componentes de Materiais Pedagógicos e de Rede Física foram realocados para os componentes de Capacitação de Professores e Desenvolvimento Institucional (Banco Mundial, 2002).

No projeto Nordeste II, os recursos poderiam ser suspensos e transferidos de um estado para outro. Os recursos seriam suspensos se as reformas gerenciais definidas em seu Plano Operacional não ocorressem; as Metas Anuais de Eficiência Gerencial demonstrassem ambiguidade; ou a implementação dos demais componentes do projeto apresentassem sérias deficiências (Banco Mundial, 1993).

Nas "lições aprendidas" pelo Banco Mundial, um dos fatores considerados fundamentais para o sucesso dos projetos é o sistema de programação, monitoramento e avaliação. Essa condição justificou a necessidade de assistência técnica com a participação de consultores 
nacionais e internacionais em várias atividades, entre elas o processo de implementação do Sistema de Avaliação da Educação Básica (SAEB), conforme o previsto no projeto Nordeste II, e a seleção e distribuição de livros didáticos. O Ministério e os estados contemplados pelo projeto Nordeste II concordaram em implementar, de forma piloto, um processo alternativo de seleção e distribuição de livros, com a assistência de consultores internacionais. Visando apoiar o desenvolvimento de recursos humanos na mensuração, avaliação e aplicação de testes educacionais, o projeto financiaria bolsas de estudo para treinamento de alto nível em institutos de pesquisa, universidades e centros de examinação qualificados, tanto nacionais quanto estrangeiros (Banco Mundial, 1993).

Os projetos financiados para o ensino fundamental brasileiro contribuíram para a implementação da política de avaliação, bem como incentivaram a concorrência entre os estados, as instituiçóes escolares e os integrantes nelas envolvidos. Nesse processo, a avaliação é considerada um mecanismo capaz de promover a qualidade, uma vez que possibilitaria o controle público dos resultados. As ações em direção à qualidade e à produtividade orientaram o processo de avaliação e o incentivo à concorrência, por exemplo, nos estados do Nordeste, de Minas Gerais, Paraná e São Paulo.

O critério de seleção, concebido como um dos mecanismos para incentivar a concorrência, foi utilizado para selecionar os estados do Nordeste em dois projetos distintos: o Nordeste II e o Nordeste III. O argumento pautou-se na crença de que o "modelo competitivo", para a seleção dos estados, constituiria um estímulo importante para a realização de reformas administrativas, bem como para a redução de despesas com mão-de-obra. Os estados contemplados pelo projeto Nordeste II foram selecionados em conjunto pelo Banco Mundial e pelo Ministério da Educação (MEC) considerando: “(...) i) a qualidade e o caráter inovador dos planos de investimentos (...); e ii) o compromisso deles em implementar importantes reformas na administração da educação estadual" (Banco Mundial, 1993, p. 28).

A necessidade do MEC em supervisionar e apoiar a educação básica estava indicada no Programa Nacional do projeto Nordeste II. Dentre as ações que foram previstas e efetivadas destacam-se: o processo de avaliação nacional sistemática do desempenho do sistema escolar, que incluiu a realização de testes padronizados sobre o aproveitamento estudantil, a partir do SAEB; a análise e disseminação política de inovações 
Os projetos financiados pelo Banco Mundial para o ensino fundamental no Brasil

educacionais eficazes; e a transferência de recursos financeiros aos estados e municípios destinados a reduzir as desigualdades por estudante (Banco Mundial, 1993).

O estado de Minas Gerais participou, em 1990, do Sistema de Avaliação da Educação Básica (SAEB) e, em 1992, a Secretaria de Estado da Educação estabeleceu o Programa de Avaliação da Escola Pública de Minas Gerais (Banco Mundial, 1994).

No estado do Paraná, a Avaliação do Rendimento Escolar traduziu, como no estado de Minas Gerais, a política de avaliação centralizada, sob o argumento de melhorar a qualidade de ensino. Desse modo, destacou-se que, no PQE/PR, “(...) o mais importante, uma cultura de autoavaliação com base em informaçôes periódicas precisas permeou a Secretaria de Estado da Educação em seus vários níveis, desde as escolas até os níveis mais altos" (Banco Mundial, 2002, p. 22).

Em 1994, no estado de São Paulo, a Secretaria de Educação realizou provas nas $4^{\mathrm{a}}$ e $8^{\mathrm{a}}$ séries e, em 1996 , realizou as provas nas $3^{\mathrm{a}}$ e $7^{\mathrm{a}}$ séries de todas as escolas estaduais (São Paulo, 1996).

Em São Paulo, no projeto de Educação Continuada 1996-1998, definiu-se que a avaliação contemplaria todos os seus segmentos de abrangência. O projeto de Educação Continuada 1996-1998 voltou-se ao objetivo máximo do Projeto Inovações no Ensino Básico, visando a uma educação de qualidade preferencialmente para as regióes de grande carência de recursos. O Contrato de Empréstimo n. 3.375-BR, entre o Governo do Estado de São Paulo e o Banco Mundial, financia parcialmente o Projeto Inovações no Ensino Básico. Esse projeto, por meio do componente Avaliação e Divulgação, previu o financiamento para a realização de estudos, objetivando avaliar e acompanhar a execução das inovações (São Paulo, 1996).

Associada ao processo de avaliação, a concorrência é concebida como um dos mecanismos para enfrentar o fracasso escolar. O componente "inovações educacionais" previu o financiamento direto para as escolas que apresentassem projetos inovadores para combater a repetência, estabelecendo, assim, a competição entre as escolas (Tommasi, 1998).

No Programa Estadual, do projeto Nordeste II, estava previsto um Fundo de Inovações. O Fundo, administrado pelo MEC, sob o patrocínio da Secretaria do Ensino Fundamental, seria para proporcionar um estímulo especial aos sistemas escolares, estaduais e municipais, 
que adotassem inovações educacionais promissoras, visando reduzir a repetência (Banco Mundial, 1993).

No Paraná, a competição entre as instituições escolares públicas realizou-se com a participação numa competição nacional (Prêmio Nacional de Referência em Gestão Escolar), pois o subcomponente instituição de um fundo de premiação não foi implementado com recursos do PQE. O Prêmio Nacional de Referência em Gestão Escolar teve a finalidade de promover a competição entre as escolas com mais de 100 alunos e um dos objetivos era a demonstração de resultados excelentes em termos de aprovação (Banco Mundial, 2002).

Em 1991, no estado de Minas Gerais, a Secretaria da Educação adotou um sistema de seleção competitiva de diretores. Também estava previsto que as escolas que contribuíssem para a consecução dos objetivos do projeto seriam recompensadas por meio do Programa de Apoio às Inovações Escolares (PAIE), do subprojeto Melhoria da Infraestrutura e Gestão da Escola. O pAIE forneceria fundos adicionais que seriam distribuídos de forma competitiva entre as escolas que apresentassem propostas de intervenções diretamente relacionadas ao aumento da aprendizagem, visando reduzir a repetência. A avaliação do mérito seria realizada por uma comissão composta de consultores brasileiros e estrangeiros, sob a supervisão da Secretaria de Estado da Educação de Minas Gerais (Banco Mundial, 1994).

Como em Minas Gerais, no Paraná também houve seleção dos diretores. Os candidatos à direção das escolas estaduais foram submetidos a um teste, elaborado pela Universidade Federal do Paraná. Todos os diretores nomeados participariam de cursos sobre gestão administrativa e pedagógica, em Faxinal do Céu, no Centro de Capacitação instalado pelo governo estadual do Paraná (Banco Mundial, 2002).

No Brasil, de acordo com o Banco Mundial, as ineficiências setoriais vêm resultando das políticas e práticas que falham ao enfrentar o problema da baixa produtividade escolar. Considera-se que o principal problema do ensino brasileiro não é o acesso e sim o rendimento escolar. Assim, os fatores que mais contribuíram para a baixa qualidade e a baixa eficiência do ensino público brasileiro teriam sido: as estratégias de ensino inapropriadas; a "cultura da repetência"; a gestão ineficiente; os gastos inadequados; e a alocação ineficiente de recursos. Argumenta, dessa forma, que com níveis menores de repetência 
Os projetos financiados pelo Banco Mundial para o ensino fundamental no Brasil

e fluxos escolares mais eficientes, mais recursos poderiam ser concentrados na melhoria da qualidade do ensino (Banco Mundial, 1993; 1994).

Neste sentido, a ênfase para enfrentar o fracasso escolar considerou, além dos critérios de avaliação e de concorrência, que supostamente resultariam na qualidade da educação, os critérios de racionalidade econômica (relação custo-benefício) e de produtividade (eficiência interna e externa).

$\mathrm{Na}$ educação, a necessidade de promover reformas institucionais e administrativas, visando melhorar a qualidade do ensino, estaria circunscrita ao parâmetro da racionalidade econômica. Desde a década de 1970, o Banco Mundial destaca a necessidade de apoiar o desenvolvimento de métodos de aprendizagem que permitam economizar recursos, bem como de estimular os países, cujas taxas de escolarização primária são baixas, a realizar uma revisão das estruturas educacionais (Banco Mundial, 1975).

A necessidade de realizar reformas institucionais e administrativas, portanto, tem como parâmetro a racionalidade econômica dos investimentos do setor público, sob o argumento de que se deve alcançar a eficiência nos gastos e a qualidade na educação, conforme se identificou nos projetos "Educação Básica no Nordeste I" (EDURURAL), "Inovações na Educação Básica em São Paulo" (Inovações) e Nordeste II.

No projeto "Educação Básica no Nordeste I" (EDURURAL), bem como no projeto "Inovaçōes na Educação Básica em São Paulo" (Inovaçôes), contemplou-se um componente importante de pesquisa e avaliação para verificar os investimentos em educação que apresentassem melhor relação custo-efetividade na melhoria da aprendizagem e no desempenho escolar de alunos, cujas famílias têm baixa renda (Banco Mundial, 1994).

O projeto Nordeste II visou à redução das taxas de evasão e repetência. A ênfase era alcançar a racionalização dos níveis de gastos nos quatro estados contemplados pelo projeto. A racionalização efetivar-se-ia por meio de reduções do quadro de pessoal e realocaçôes das despesas para os materiais didáticos e o treinamento dos professores, com o que se esperava elevar a qualidade, traduzida em fluxos mais eficientes nos sistemas de ensino estadual e municipal (Banco Mundial, 1993).

Os programas e projetos implementados nas décadas de $1980 \mathrm{e}$ de 1990, no ensino fundamental, contribuíram para melhorar o fluxo 
escolar, por meio da chamada promoção automática e da correção da defasagem idade-série; condiçôes consideradas necessárias para alcançar os critérios de produtividade e de racionalidade econômica.

O Ciclo Básico de Alfabetização (CBA), com promoção automática, nos estados de “(...) São Paulo (1984), Minas Gerais (1985), Paraná e Goiás (1988) (...)” (Mainardes, 1995, p. 3), as Classes de Aceleração, em São Paulo, a Aceleração da Aprendizagem, em Minas Gerais, e o Programa Correção de Fluxo, no Paraná, foram algumas das principais políticas implementadas para garantir a melhoria do fluxo escolar.

No estado do Paraná, o CBA iniciou com a aprovação automática na primeira e segunda série e, posteriormente, em 1993, esse "continuum" foi adotado no estado do Paraná da primeira à quarta série (Banco Mundial, 2002).

No projeto financiado pelo Banco Mundial, em Minas Gerais, destacou-se que a melhoria do fluxo escolar seria condição para aumentar a eficiência dos gastos públicos com educação primária, pois, com fluxos de alunos mais eficientes nas escolas primárias, os gastos com educação poderiam ser destinados à melhoria da qualidade do ensino (Banco Mundial, 1994).

Em Minas Gerais, inicialmente o CBA correspondeu ao período equivalente às $1^{\mathrm{a}}$ e $2^{\mathrm{a}}$ séries do ensino fundamental, unificado num mesmo bloco. A partir de 1996, о CBA foi estendido à $3^{a}$ série do ensino fundamental, a partir da Resolução n. 7.915/1996 (Oliveira, 2000).

Em São Paulo, a instituição do Ciclo Básico no ensino fundamental ocorreu por meio do Decreto n. 21.833/1983. Em 1984, o Ciclo Básico é regulamentado, por meio da Resolução SE 13, fixando as normas e publicando o regulamento (Borges, 2002).

O Ciclo Básico de Alfabetização, portanto, juntamente com os programas Correção de Fluxo, Classes de Aceleração e Aceleração da Aprendizagem, garantiram a melhoria do fluxo escolar e o critério da racionalidade econômica.

No estado do Paraná, o Programa Correção de Fluxo foi realizado no decorrer do desenvolvimento do PQE. O componente Material Pedagógico foi expandido para incluir a impressão de material didático a ser utilizado no programa. A melhoria da eficiência em termos de índices de redução na reprovação e evasão escolar, revelando a economia de recursos gastos no sistema educacional, com o PQE/PR, confirma a lógica da 
Os projetos financiados pelo Banco Mundial para o ensino fundamental no Brasil

racionalidade econômica do Programa Correção de Fluxo, quando o relatório do Banco Mundial estimou que até US\$ 80 milhões por ano foram gastos com reprovação antes do projeto. $\mathrm{Na}$ avaliação do Banco Mundial, no geral, o PQE/PR alcançou substancialmente seus objetivos, conduzindo a uma importante redução nos índices de reprovação e evasão na educação fundamental paranaense, o que resultou em aumento de eficiência e custo mais baixo por aluno (Banco Mundial, 2002).

No estado de São Paulo, o projeto Reorganização da Trajetória Escolar no Ensino Fundamental (Classes de Aceleração) também visou recuperar a trajetória dos alunos em situação de defasagem idade-série, a partir de classes que desenvolvessem uma proposta de aceleração de aprendizagem para integrar os alunos no percurso regular do ensino fundamental (São Paulo, 1996).

Diante dos altos índices de defasagem idade-série, a Secretaria da Educação de Minas Gerais criou os programas especiais de Aceleração da Aprendizagem, a partir da Resolução n. 8.287/1998 (Oliveira, 2000, p. 303).

No projeto Nordeste II, no componente Treinamento de Professores e Diretores de Escolas, destacou-se a necessidade de utilização efetiva de novos materiais pedagógicos a serem fornecidos pelo projeto, incluindo novos métodos de gerenciamento de tempo em classe, bem como de novas estratégias de ensino para reduzir a repetência, como o reforço de aprendizado para alunos lentos, e padrões de promoção mais flexíveis (Banco Mundial, 1993).

O financiamento externo à educação brasileira, nas décadas de 1980 e 1990, suscitou a indagação sobre a sua real necessidade, tendose em conta, por exemplo, as despesas decorrentes dos empréstimos e os resultados educacionais.

Os financiamentos do BIRD à educação brasileira representam um negócio caro para o setor (...). A análise dos resultantes educacionais, institucionais e financeiros decorrentes da cooperação técnica do BIRD à educação brasileira, mostra que a experiência desenvolvida durante duas décadas, na forma de co-financiamento, constitui um processo caro, complexo do ponto de vista administrativo e ineficaz quanto aos resultados educacionais. (Fonseca, 1998, p. 114-116) 
Além das altas despesas adicionais (financeiras e administrativas) que acarretam para o setor educacional e para o país, existem outras dificuldades, entre elas, a avaliação dos projetos.

A desconsideração dos resultados de experiências anteriores facilita a reiteração de equívocos na definição dos projetos como, por exemplo, a aceitação de cláusulas financeiras e outras condicionalidades que irão conflitar com a organização institucional brasileira (...). Assinale-se, ainda, a dificuldade de se contar com o conhecimento do processo como um todo (...). Como conseqüência, o Banco passa a ser o único detentor das informaçóes completas sobre o processo e os resultados da cooperação (...). Uma outra causa da continuidade do financiamento internacional é, sem dúvida, a ausência de informações que mostrem a sua real contribuição à educação nacional, ao longo de sua evolução histórica (...). Assim, aqueles objetivos que não lograram impor-se na prática, ao longo de vinte anos de experiência, são acolhidos como propostas inovadoras. (Fonseca, 1998, p. 104-105-119. Grifos nossos)

É preciso mencionar que, de forma destacada, a partir da década de 1970 "o endividamento externo tornou-se um dos principais mecanismos, se não o mais importante, no processo de internacionalização financeira da economia brasileira" (Deitos, 2005, p. 62), no qual estão inseridos os financiamentos para a educação. Dessa forma, o BIRD e o Banco Interamericano de Desenvolvimento (BID) “(...) têm sido responsáveis pela transferência líquida de recursos do Brasil para o exterior. Ou seja, pagamos mais juros e amortizações do que estes desembolsam de novos empréstimos" (Soares M., 1995, p. 11). Em relação a alguns empréstimos do BIRD ao Brasil é possível verificar que no período de 1980 a 1997 o país realizou pagamentos de US\$17,1 bilhôes e recebeu US\$14,3 bilhōes. Desse modo, foram transferidos US\$ 2,8 bilhões ao BIRD. Além disso, esses empréstimos deixaram o país com uma dívida, em 31/12/ 1997, de US\$ 5,3 bilhôes (Soares R., 1999, p. 35).

Em síntese, na década de 1990, os projetos financiados para o ensino fundamental brasileiro, pelo Banco Mundial, objetivaram enfrentar o fracasso escolar, interpretado como indicador de ineficiência e falta de qualidade. Os componentes ou programas de ação dos projetos financiados para o ensino fundamental priorizaram orientações e propostas pautadas em critérios gerenciais para promover a concorrência, a qualidade, a produtividade e a racionalidade econômica. Dessa 
forma, subjacente à política de enfrentamento do fracasso escolar, verificamos, além dos critérios de avaliação e de concorrência, os critérios de produtividade e de racionalidade econômica.

Recebido em abril de 2007 e aprovado em agosto de 2007.

\section{Referências}

BANCO MUNDIAL. Educación: documento de política sectorial. Washington, DC, 1975.

BANCO MUNDIAL. Segundo Projeto Nordeste de Educação Básica. Relatório de avaliação prévia n. 11298-BR. Washington, DC, abr. 1993.

BANCO MUNDIAL. Projeto de Melhoria da Qualidade da Educação Básica em Minas Gerais (Pró-Qualidade). Relatório de Avaliação n. 12477-BR. Washington, DC, 1994.

BANCO MUNDIAL. Prioridades y estrategias para la educación: estudio sectorial del Banco Mundial. Versão preliminar. Washington, DC, maio 1995.

BANCO MUNDIAL. Educação primária: documento de política do Banco Mundial. Washington, DC, 1992. apud TORRES, M. R. Melhorar a qualidade da educação básica? As estratégias do Banco Mundial. In: Tommasi, L.; Warde, M. J.; Haddad, S. (Org.). O Banco Mundial e as politicas educacionais. 2.ed. São Paulo: Cortez; 1998.

BANCO MUNDIAL. Projeto de Melhoria no Ensino Público do Paraná. Relatório da conclusão da implementação. 2002. (Empréstimo n. 3.766-BR).

BORGES, Z.P. Política e educação: análise de uma perspectiva partidária. Campinas: FE/UnICAMP; Hortograph, 2002.

DEITOS, R.A. O capital financeiro e a educação no Brasil. 2005. Tese (Doutorado em Educação) - Faculdade de Educação, Universidade Estadual de Campinas, Campinas.

FIGUEIREDO, I.M.Z. Desenvolvimento, globalização e políticas sociais: um exame das determinaçôes contextuais dos projetos de reforma da educação e da saúde brasileiras da última década. 2006. Tese (Doutorado 
em Educação) - Faculdade de Educação, Universidade Estadual de Campinas, Campinas.

FONSECA, M. O financiamento do Banco Mundial à educação brasileira: 20 anos de cooperação internacional. In: TOMMASI, L.; WARDE, M.J.; Haddad, S. (Org.). O Banco Mundial e as politicas educacionais. 2. ed. São Paulo: Cortez, 1998a.

FONSECA, M. O Banco Mundial e a educação brasileira: uma experiência de cooperação internacional. In: Oliveira, R. P. (Org.). Política educacional: impasses e alternativas. 2. ed. São Paulo: Cortez, 1998b.

GONZALEZ, M.J.F. et al. O Brasil e o Banco Mundial: um diagnóstico das relações econômicas: 1949-1989. Rio de Janeiro: IPEA/sEPLAN, 1990 .

HADDAD, S. Os bancos multilaterais e as políticas educacionais no Brasil. In: Viana Junior, A. (Org.). A estratégia dos bancos multilaterais para o Brasil: análise crítica e documentos inéditos. Brasília, DF: Rede Brasil sobre Instituiçôes Financeiras Multilaterais, 1998.

LEHER, R. Da ideologia do desenvolvimento à ideologia da globalização: a educação como estratégia do Banco Mundial para "alívio" da pobreza. 1998. Tese (Doutorado em Educação). Faculdade de Educação - Universidade de São Paulo, São Paulo, SP.

MAINARDES, J. Ciclo básico de alfabetização: da intenção à realidade; avaliação do CBA no município de Ponta Grossa-PR. 1995. Dissertação (Mestrado em Educação) - Faculdade de Educação, Universidade Estadual de Campinas, Campinas.

OLIVEIRA, D.A. Educação básica: gestão do trabalho e da pobreza. Petrópolis: Vozes, 2000.

OLIVEIRA, D.A.; FONSECA, M. O Banco Mundial e as políticas de formação docente: a centralidade da educação básica. In: Hidalgo, A.M. et al. (Org.) Educação e Estado: as mudanças nos sistemas de ensino do Brasil e Paraná na década de 90. Londrina: UEL, 2001.

SÃO PAULO (Estado). Secretaria de Estado da Educação. Projeto de educação continuada 1996-1998. São Paulo, jul. 1996. 
SOARES, M.C.C. A importância dos bancos multilaterais na conjuntura atual. In: Seminário Banco Mundial e BID no Brasil: perspectivas de ação para a sociedade civil. Brasília, DF, 21 mar. 1995. (mimeo).

SOARES, M.C.C. Banco Mundial: políticas e reformas. In: TOMMASI, L.; Warde, M.J.; Haddad, S. (Org.). O Banco Mundial e as políticas educacionais. 2. ed. São Paulo: Cortez, 1998.

SOARES, R.P. Divida pública externa: empréstimos do BIRD ao Brasil. Brasília, DF: IPEA, 1999. (Texto para discussão, 642)

TOMMASI, L. Financiamentos do Banco Mundial no setor educacional brasileiro: os projetos em fase de implementação. In: TOMMASI, L.; Warde, M.J.; Haddad, S. (Org.). O Banco Mundial e as politicas educacionais. 2. ed. São Paulo: Cortez, 1998. 